\title{
What Remains from the Volcker Experiment?
}

\author{
Benjamin M. Friedman
}

4 ssessing the lasting impact of any experiment in economic policymaking requires, first of all, understanding in what key respects that experiment represented a departure from prior established practice. The new policymaking framework that the Federal Reserve System began to employ in October 1979 is no exception. Specific quantitative targets for growth of the money stock, or for either borrowed or nonborrowed reserves in the banking system, have long since disappeared from the Federal Reserve's approach to formulating and implementing monetary policy. Yet there remains a widespread sense that the world of monetary policymaking in the United States has been somehow different since 1979. What exactly is different, and in what respects those differences stem from the innovations introduced in 1979, are questions well worth addressing.

The conventional representation of economic policymaking, applicable to monetary policy no less (and maybe far more readily) than to other familiar contexts, posits a policymaker deploying whatever instruments may be available to best achieve a finite set of typically conflicting objectives, subject to the constraints presented by existing institutional arrangements and technology and by the behavior of the relevant actors in the economy's private sector. In the specific case of monetary policy, the policy problem is simplified because the central bank normally has only one genuine instrument at its disposal-namely, its provision of reserves to the economy's banking system. ${ }^{1}$ The problem is also more complex, how-

1 As a technical matter, the central bank can also typically adjust the amount of reserves (if any) that banks are required to maintain ever, because the central bank is free to specify its provision of reserves in terms of either the quantity of reserves or their price (in other words, the relevant interest rate). ${ }^{2}$ Yet a further complexity arises in that the central bank's provision of reserves (or setting of the interest rate) affects the aspects of economic activity policymakers are seeking to influence only over time. As a result, under some circumstances it may be helpful to formalize ways of exploiting information about what is happening in the meanwhile by focusing policy on still other observable aspects of economic activity-in this instance, the most obvious example is the money stock-that of course differ from the genuine objectives being pursued but that may provide some indication of the extent to which those objectives are being achieved.

Thinking about monetary policy in this familiar way provides a structured framework for asking what was, or is, new about any specific innovation: (i) Is it a change in the objectives that policymakers are seeking to achieve? (ii) Is it a change in the choice of policy instrument-in the case of monetary policy, the quantity versus the price dimension in the provision of reserves? (iii) Is it a change in the way auxiliary aspects of economic activity are being used to steer policy in the context of time lags in the effect of central bank actions on the ultimate objectives of monetary policy?

in relation to their outstanding deposits. But under most circumstances, changes in reserve requirements and changes in the provision of reserves are equivalent for purposes relating to the broad macroeconomic objectives of monetary policy.

2 It is also possible to specify the central bank's provision of reserves in terms of some combination of quantity and price (that is, a reserve-supply function with positive but finite elasticity). 


\section{Friedman}

Most public discussion of the Volcker experiment at the time emphasized (ii) and (iii)—in particular, the joint implication that under the new policymaking framework market interest rates (the facet of monetary policy of which most citizens are most acutely aware) were now free to fluctuate far more freely than in the past. The subsequent academic literature has likewise mostly focused on either (ii) or (iii). With time, however, what was new with regard to neither (ii) nor (iii) has survived. If there has been anything lasting from the apparent sea change of October 1979, therefore, it lies in (i).

To be specific, the broad public discussion of the Federal Reserve's new approach in 1979 primarily emphasized the elevation of quantitative money growth targets-element (iii)—from the irregular and mostly peripheral role they had played, beginning in the early 1970s, to center stage: The Federal Open Market Committee (FOMC) decided what money growth it sought going forward and articulated its policy in terms of what open market operations the System Account needed to conduct to keep the money stock as close as possible to the targeted trajectory.

The subsequent history of money growth targets for monetary policy, in the United States as well as elsewhere, is thoroughly well-known and need not be reviewed in any detail. Almost immediately after October 1979, actual events belied the conventional presumption among most advocates of money growth targets that the major monetary aggregates would move roughly in synchrony so that choosing just which among them was the right one to target was at best a secondary consideration. Prominent monetarist economists publicly argued that policy was too easy, or too tight, depending on which measure they chose to emphasize. The FOMC had chosen to place primary emphasis on the narrow M1 aggregate, but by 1982 that measure displayed so little tie to either income growth or price inflation that the Committee formally moved away from it. Evidence since then shows that by the mid-1980s M1 had disappeared altogether as an observable influence on policymaking, and the same happened to the broader M2 measure by the early $1990 s .{ }^{3}$ In 1987 the FOMC stopped setting a target for M1 growth, and in 1993 the Federal Reserve publicly acknowledged the "downgrading" of its M2 target-a change that most observers of U.S. monetary policy had already noticed well before then.

The reasons for the breakdown of what had seemed to be longstanding relationships (though in fact even then they were probably less reliable than they appeared) between money and income, or money and prices, have also been thoroughly studied. The standard list includes financial innovation, deregulation, and globalization of markets for deposits and other closely substitutable financial assets. But the main point here is simply that the reliance on money growth targets that was key to at least the public presentation of the new monetary policy regime in 1979 has now entirely disappeared.

The same is true for element (ii), the use of, in turn, several variants of an open market operating procedure based on the quantity of either nonborrowed or borrowed reserves. In part, the 1979 change in (ii) was a consequence of the change in (iii): Once the proximate objective of policy was to control money growth, doing so by fixing a measure of reserves month-to-month seemed likely to deliver better results than fixing the overnight interest rate. In time this presumption too came to appear doubtful. But the issue became moot because the FOMC abandoned money growth targets anyway.

The only way some version of a reserves-based operating procedure could have survived, once the money growth targets were gone, would have been if policymakers thought the relationship between reserves growth and economic activity was more reliable than the relationship between interest rate growth and economic activity. Few economists have been prepared to make that case. ${ }^{4}$

\footnotetext{
3 See Friedman (1997) for a review of this evidence, but the associated empirical literature is vast.

4 Following the enormous body of work by Brunner and Meltzer, and in more recent times by McCallum, many economists have argued for a reliable relationship between economic activity and the monetary base. The key difference is that the monetary base includesindeed, mostly consists of-currency in circulation. Hence, the base may or may not be a plausible replacement for money stock as an intermediate target of monetary policy, but it is not a plausible short-run operating instrument.
} 
As a result, the Federal Reserve has gone back to carrying out monetary policy by fixing a shortterm interest rate-in the modern context, the overnight federal funds rate-just as it did for decades prior to $1979 .{ }^{5}$

That leaves (i). Did the Volcker experiment represent a new, presumably greater weighting attached to achieving "price stability" vis-a-vis the other objectives of monetary policy? And, if so, has that greater weighting survived?

The post-1979 record of price inflation in the United States surely creates some prima facie presumption to this effect. After reaching either near double-digit levels (the gross domestic product deflator) or low double-digit levels (the consumer price index) in the late 1970s, inflation dropped to roughly 4 percent per annum in the 1980s, then 3 percent and eventually 2 percent in the 1990s. Cyclical considerations perhaps obscure the underlying trend in the current decade, but to date there is certainly no clear indication of resurgent inflation beyond the 2 to 3 percent per annum range. More to the point, the impression is both widespread and confident that, were such a resurgence to begin to develop, the Federal Reserve would act vigorously to resist and reverse it.

Does this, however, represent a genuine change in the weighting placed on inflation among policymakers' sometimes competing objectives, plausibly one that can be dated to October 1979? Or is there some other explanation, independent of the Volcker experiment?

One point worth making explicitly is that, to the extent that one standard objective of monetary policy is smoothness in short-term interest rates, there is no evidence that the increased tolerance for interest rate fluctuations that the Federal Reserve exhibited during the Volcker period has survived. One of the most frequent criticisms of monetary policy operating procedures based on fixing short-term nominal interest rates is that central banks have traditionally proved too hesi-

\footnotetext{
5 During some periods before 1979, the FOMC specified its policy in terms of the net free-reserves position of the banking system, but most Federal Reserve economists (and most market participants) understood that net free reserves was a close proxy to short-term interest rates.
}

tant to adjust the interest rates they set, and when they do move interest rates they have tended to do so too slowly. The usual explanation is that, in addition to their objectives for such macroeconomic variables as price inflation and the growth of output and employment, central banks also take seriously their responsibility to maintain stable and well-functioning financial markets, together with the (more questionable) assumption that sudden or wide fluctuations in short-term interest rates are inimical to achieving that goal. For this reason, now-conventional expressions of operating rules for monetary policy, such as the Taylor rule, normally include a lagged interest rate along with measures of inflation and output (or employment) relative to the desired benchmark. ${ }^{6}$

Part of what distinguished the Volcker experiment was the unusually wide (albeit not totally unconstrained) fluctuations of short-term interest rates that occurred under the Federal Reserve's quantity-based operating procedures. (Indeed, one element of the folklore surrounding the entire episode is the claim that the adoption of money growth targets, and the reserves-based operating procedure that went with them, was in part simply a diversion that enabled the Federal Reserve to put in place far higher interest rates than would otherwise have been politically possible.) Merely glancing at a chart showing the time path of interest rates in recent years immediately shows that no such fluctuations have been allowed to occur. Might the Federal Reserve again permit them if doing so seemed necessary to rein in incipient inflation? Perhaps so, but on the evidence there is no ground for claiming that this aspect of the 1979 experiment has survived either.

What remains, then, is the question of whether 1979 brought a new, greater weight on the Federal Reserve's objective of price stability vis-a-vis its objective of output growth and high employment. To be sure, that is one interpretation of the historical experience both before 1979 and after. But there are other interpretations as well, especially in light of the record not just in the few years immediately preceding 1979 but substan-

6 See also Barro (1989) for a theoretical analysis of the implications of interest rate smoothing as a part of monetary policy. 
tially before as well. The United States experienced little inflation in the 1950s and not much in the 1960s either. ${ }^{7}$ Hence, the historical evidence is also consistent with the view that the 1970s were exceptional rather than that the experience since 1979 has differed from what went before as a whole.

Even the idea that the Volcker experiment represented a return to the greater policy weight on price stability vis-a-vis real outcomes that had motivated the Federal Reserve before the 1970s, and that this renewed commitment to price stability has lasted ever since, would make the events of 1979 a major and lasting contribution to U.S. monetary policymaking. But here, as well, other explanations are also possible. For example, perhaps policymakers in the 1970s were just as committed to the objective of price stability as they were before and have been since, but required some significant experience in an inflationary environment in order to understand, and begin to respond appropriately to, the newly relevant distinction between nominal and real interest rates. Perhaps policymakers in the 1970 s were no less committed to the objective of price stability but were operating under a different (in retrospect, some have argued, a flawed) understanding of the broader economic behavior constraining the relationship between their actions and the resulting policy outcomes. ${ }^{8}$ Perhaps policymakers were no less committed to price stability but simply faced an extraordinary sequence of macroeconomic shocks (OPEC, anchovies, etc.) that were, temporarily, adverse from the perspective of achieving either price stability or desired rates of real growth and levels of unemployment. ${ }^{9}$

Resolving the merits of these and other potential interpretations of the historical recordinterpretations that, importantly, are in no way

\footnotetext{
7 Before the Treasury-Federal Reserve Accord in 1951, monetary policy was constrained by the wartime commitment to fix interest rates. Before then, the Depression rendered the question moot. Drawing inferences from the pre-Depression experience seems of little relevance to this discussion.

8 Two examples of arguments along these lines are DeLong (1997) and Sargent and Cogley (2005).

9 This too is a familiar argument. For a contemporary statement, see Blinder (1979). See Orphanides (2004) for a particularly interesting recent reincarnation.
}

mutually inconsistent-is surely a worthwhile object of empirical research. It is also a necessary underpinning of any judgment of whether what happened in October 1979 actually represented a change in the weight that policymakers attach to the objective of price stability.

Finally, one further aspect of what 1979 may or may not have been about bears attention. Perhaps what was important about the changes represented by (iii), and in a subsidiary way, then, by (ii), was not the specifics of money growth targets and reserves-based operating procedures but rather the concrete expression that they embodied of the desire in many quarters to impose some form of ongoing discipline on the monetary policymaking process-in the traditional language of this subject, to impose "rules" where there had been "discretion."

Whether the use of money growth targets, with the FOMC free to choose and then change the target as it saw fit, did or did not qualify as a kind of "rule" in this context is a matter of debate, in part substantive and in part semantic. But to the extent that it was a form of rule for this purposeand the argument for money growth targets has often been made on just those grounds-it, too, clearly failed to survive. Federal Reserve policymaking in recent years has epitomized what "discretion" in monetary policy has always been about.

Precisely for this reason, advocates of rules over discretion today continue to seek some way of moving Federal Reserve policymaking in that direction. The proposal of this kind that has attracted the most interest currently is "inflation targeting." Whether adopting inflation targeting would be a good or bad step for U.S. monetary policy is a separate issue. ${ }^{10}$ But one reason the issue is even on the agenda today is that the movement in this direction that the experiment of October 1979 represented did not last either.

\section{REFERENCES}

Barro, Robert J. "Interest-Rate Targeting.” Journal of Monetary Economics, January 1989, 23, pp. 3-30.

\footnotetext{
${ }^{10}$ For a compact statement of the views on either side, see Mishkin (2004) and Friedman (2004).
} 
Blinder, Alan S. Economic Policy and the Great Stagflation. New York: Academic Press, 1979.

DeLong, J. Bradford. “America's Peactime Inflation: The 1970s," in Christina D. Romer and David H. Romer, eds., Reducing Inflation: Motivation and Strategy. Chicago: University of Chicago Press, 1997.

Friedman, Benjamin M. "The Rise and Fall of Money Growth Targets as Guidelines for U.S. Monetary Policy," in Iwao Kuroda, ed., Towards More Effective Monetary Policy. Houndmills: Macmillan Press, 1997.

Friedman, Benjamin M. "Why the Federal Reserve Should Not Adopt Inflation Targeting." International Finance, March 2004, 7, pp. 129-36.

Mishkin, Frederic S. "Why the Fed Should Adopt Inflation Targeting." International Finance, March 2004, 7, pp. 117-27.

Orphanides, Athanasios. "Monetary Policy Rules, Macroeconomic Stability, and Inflation: A View from the Trenches." Journal of Money, Credit, and Banking, April 2004, 36, pp. 151-75.

Sargent, Thomas J. and Timothy, Cogley. "The Conquest of U.S. Inflation: Learning, Model Uncertainty, and Robustness." Review of Economic Dynamics, 2005 (forthcoming). 
